\title{
Distinct microbial composition and functions in an underground high-temperature hot spring at different depths
}

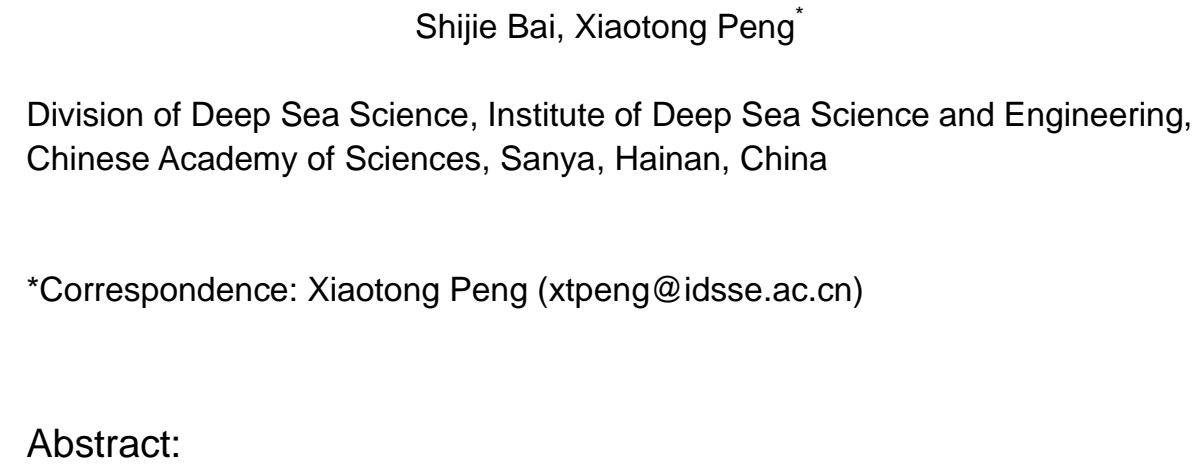

The microbial diversity and functions of three high-temperature neutral hot springs water samples at different depths $(0 \mathrm{~m}, 19 \mathrm{~m}$ and $58 \mathrm{~m})$ were investigated based on 16S rRNA gene sequencing and a functional gene array (GeoChip 5.0). The results revealed that the bacterial communities were distinct at different depths in the hot springs. Additionally, in response to the depths, bacterial/archaeal community compositions exhibited shifts over the depth profiles. Aquificae, Alpha-proteobacteria, and Deinococcus-Thermus were the dominating phyla at $0 \mathrm{~m}, 19 \mathrm{~m}$, and $58 \mathrm{~m}$, respectively. Hydrogenobacter, Sphingobium, and Thermus were the most abundant genera at $0 \mathrm{~m}, 19 \mathrm{~m}$, and $58 \mathrm{~m}$, respectively. The phylum Thaumarchaeota was the most abundant member of the archaeal community in the samples at different hot spring depths. Functional results of the microbial communities indicated that microbial metabolic functions were mainly related to sulfur, nitrogen cycling, and hydrogen oxidation. In summary, our 
26 results demonstrated that distinct microbial communities and functions were

27 found at different depths of hot springs in a very limited area. These findings will

28 provide new insights into the deep-subsurface biosphere associated with

29 terrestrial hot springs.

31 Keywords: Hot springs, Microbial diversity, Functions, Underground, High

32 temperature

Introduction

35 Extreme environments on Earth refer to those with diverse harsh environmental

36 conditions. These conditions include acid, alkaline, high salinity, high and low

37 temperatures, high metal concentrations, high radiation, and high pressures

38 (Mirete et al., 2016). Hot springs, as an extreme environment, harbor many

39 thermophilic and hyperthermophilic microbes with optimal growth temperatures >

$4055{ }^{\circ} \mathrm{C}$ and $>80{ }^{\circ} \mathrm{C}$, respectively. The initial studies of hot springs related to

41 microbes were focused on the isolation and characterization of strains using

42 traditional culture-dependent approaches (Marsh and Larsen, 1953). However,

43 since $\sim 99 \%$ of the microorganisms are uncultivable on the earth (Amann et al.,

44 1995), cultivation-independent molecular methods were developed to overcome

45 the uncultivable issue, giving support to research focused on the microbial

46 diversity using a high-throughput sequencing approach based on $16 \mathrm{~S}$ rRNA

47 genes. This method has been extensively used to uncover microbial communities 
48 and their compositions in different hot springs around the world, providing a

49 comprehensive realization of microbial diversity in hot spring environments

50 (Huang et al., 2013; Bowen et al., 2013; Kambura et al., 2016). According to

51 previous studies, hot spring environments are generally observed to be much less

52 diverse than common habitats such as wetland sediments and marine surface

53 water. Nonetheless, considering the possibility that hot spring environments may

54 have existed on our planet for more than billions of years (Gold, 1992), some

55 distinct microorganisms could adapt to the conditions via unique physical,

56 chemical, and geographical characteristics. Many microbiologists are attracted by

57 these exclusive traits and to reveal the microbial communities of hot springs

58 around the world, such as in USA (Bowen et al., 2013), Iceland (Menzel et al.,

59 2015), Russia (Rozanov et al., 2014), Kenya (Kambura et al., 2016), India

60 (Saxena et al., 2017) and China (Wang et al., 2013; Li et al., 2015; Chen et al.,

61 2016). However, most hot spring samples are taken from the surface layer, as

62 either water, mat or sediments; thus, very little is known about the microbial

63 diversity and functions under the subsurface. Therefore, knowledge regarding

64 microbial functions and diversity from depths within hot springs, which provide

65 valuable information about deep-subsurface biospheres on land, is still lacking.

66 Considering the differences in surface and deep environments, such as oxygen,

67 light, and organic and inorganic substances, the microbial composition and

68 functions should be different between the surface and deep water layers in hot 69 springs. 
Functional gene arrays (FGAs) target genes involved in various functional processes and are valuable for evaluating the functional composition and structure of microbial communities (Zhou et al., 2015). GeoChip, a generic FGA targeting hundreds of functional gene categories that are involved in important biogeochemical, ecological, and environmental studies, has been successfully applied to different environmental samples (Colin et al., 2017; Ma et al., 2017). Niujie town, located in the Eryuan county of Dali city, Yunnan province, China, is one of the most important places along the Tea-horse Caravan road between Yunan and Tibet. Tectonically, it is situated at the collision boundary between the Indian and Eurasian plates and belongs to the eastern end of the Tibet-Yunnan geothermal zone (Kearey and Wei, 1993). To gain insights into the microbial diversity and potential functions of microbial communities in hot spring waters at different depths, we performed 16S rRNA gene sequencing and functional gene array (GeoChip 5.0) (Shi et al., 2019) analysis on hot spring waters at three different depths $(0 \mathrm{~m}, 19 \mathrm{~m}$ and $58 \mathrm{~m})$. We addressed the following questions in this study: (1) are the microbial communities at different depths in a hot spring taxonomically and functionally different due to the depths and (2) how is the community functional potential altered by the depth, specifically those functions involved in the cycling of key natural elements/compounds (e.g., nitrogen, methane and sulfur). 
92 Site description and sampling

93 The study area is located in Niujie town, Eryuan county, Dali city, Yunnan

94 province, China (Fig. 1). Almost all families in this town have a hot spring well,

95 and the hot spring wells are directly connected with hot springs at different depths

96 by pipeline. Due to the various depths of well drilling, the hot spring waters from

97 different families represent hot spring waters from different depths. Three hot

98 spring water samples with different depths were taken from three hot spring wells

99 in a small area. The distance between each sampling site is less than $50 \mathrm{~m}$. The

100 temperature was measured by a DeltaTrak Waterproof Lollipop Min/Max Autocal

101 Thermometer (Model 11050, Pleasanton, CA, USA), and the pH was measured

102 by an HQd Portable Meter pH (Model HQ40d, Loveland, CO, USA). The depth

103 information of the different hot spring wells was provided by the villagers of each

104 family, and this depth information was from the drilling company after the specific

105 wells were drilled. Equal volumes of hot spring water $(80 \mathrm{~L})$ were collected from 0

$106 \mathrm{~m}, 19 \mathrm{~m}$ and $58 \mathrm{~m}$ at each hot spring wells and then filtered through $0.22-\mu \mathrm{m}$

107 polyethersulfone membrane filters (Millipore, MA, USA). The filters were

108 maintained in a box full of dry ice, transferred to the lab and then stored at -

$10980^{\circ} \mathrm{C}$ until DNA extraction.

111 DNA extraction and GeoChip 5.0 analysis

112 To obtain three duplicate samples from each hot spring well at depths of $0 \mathrm{~m}, 19$

$113 \mathrm{~m}$ and $58 \mathrm{~m}$, each of the $0.22-\mu \mathrm{m}$ filter membranes used to collect 
114 microorganisms from different hot spring wells were divided into three parts using

115 sterile scissors and forceps on a super clean bench. DNA was then extracted

116 from the filters with MoBio PowerSoil DNA Isolation Kits (Mo Bio Laboratories,

117 Carlsbad, CA, USA) according to the manufacturer's instructions.

118 For each sample, $20 \mathrm{ng}$ of DNA was taken to perform whole community 119 genome amplification with the GE Healthcare Life Sciences illustra TempliPhi

120 Amplification kit (GE Healthcare, Piscataway, NJ) (Wu et al., 2006). One

121 microgram of amplified DNA from each sample was labeled with fluorescent Cy-3

122 dye (GE Healthcare, CA, USA) by random priming as described previously (Bai et

123 al., 2013). After purification using a QIA quick Purification kit (Qiagen, CA, USA),

124 the DNA was dried in a SpeedVac (Thermo Savant, NY, USA) and rehydrated

125 with $13 \mu \mathrm{l}$ of DNase/RNase-free distilled water. A total of $42 \mu \mathrm{l}$ of buffer containing

$1261 \times$ HI-RPM hybridization buffer, $1 \times$ aCGH blocking agent, $0.05 \mu \mathrm{g} / \mu \mathrm{l}$ Cot-1 DNA,

$12710 \mathrm{pM}$ universal standard, and 10\% formamide (final concentrations) was added

128 to each sample. After mixing completely, the solution was incubated at $95^{\circ} \mathrm{C}$ for 3

$129 \mathrm{~min}$ and then incubated at $37{ }^{\circ} \mathrm{C}$ for $30 \mathrm{~min}$. The prepared samples were

130 hybridized with GeoChip 5.0 arrays $(180 \mathrm{~K})$ at $67^{\circ} \mathrm{C}$ for $24 \mathrm{~h}$. Scanned images of

131 the hybridized GeoChips were converted and extracted using the Agilent Feature

132 Extraction 11.5 software (Agilent Technologies, Inc., CA, USA). The extracted

133 information from the hybridized GeoChips was analyzed through the microarray

134 analysis pipeline on the web site (http://ieg.ou.edu/microarray/) as previously

135 described (Zhao et al., 2014). To call probes positive, we used a floating SNR so 
136 that the hyperthermophile probes accounted for $5 \%$ of the positive signals. We

137 then we removed probes considered to be negative if the signal was $<1500$ or

$138<1.3$ times the background.

16S rRNA gene amplification and Illumina Sequencing communities in each of the 12 samples, the 515F (5' -GTG CCA GCM GCC GCG GTA A-3') and 806R (5' -GGA CTA CNN GGG TAT CTA AT-3') primer set was used to amplify the V4 region of the bacterial $16 \mathrm{~S}$ rRNA gene. The Arch519F (5' -CAG CCG CCG CGG TAA-3') and Arch915R (5' -GTG CTC CCC CGC CAA TTC CT-3') primer set was used to amplify the V4 region of the archaeal 16S rRNA gene. All PCRs were carried out in $30 \mu \mathrm{l}$ reaction with $15 \mu \mathrm{l}$ of Phusion High-Fidelity PCR Master Mix (New England Biolabs, MA, USA), $0.2 \mu \mathrm{M}$ of forward and reverse primers, and approximately $10 \mathrm{ng}$ of DNA. Thermal cycling consisted of an initial denaturation at $98{ }^{\circ} \mathrm{C}$ for $1 \mathrm{~min}$, followed by 30 cycles of denaturation at $98{ }^{\circ} \mathrm{C}$ for $10 \mathrm{~s}$, annealing at $50{ }^{\circ} \mathrm{C}$ for $30 \mathrm{~s}$, and elongation at $72{ }^{\circ} \mathrm{C}$ for $60 \mathrm{~s}$, and a final elongation at $72^{\circ} \mathrm{C}$ for $5 \mathrm{~min}$. The PCR products were analyzed on a $2 \%$ agarose gel, and the target DNA was purified with the Gene

154 JET Gel Extraction Kit (Thermo Scientific). Sequencing libraries were generated

155 using the NEBNext Ultra ${ }^{\text {TM }}$ DNA Library Prep Kit for Illumina (New England

156 Biolabs). The libraries were sequenced on an Illumina MiSeq platform 2500 and

157 250-bp paired-end reads were generated at Novogene (Beijing, China). The 
158 sequencing reads were submitted to the Short Read Archive database at NCBI

159 under accession no. SRP120991 for bacterial sequences and accession no.

160 SRP121000 for archaeal sequences. for one mismatch. Pairs of reads of sufficient length were merged with at least 30 bp using the FLASH program (Magoč and Salzberg, 2011). The threshold, including a quality score $>20$ and window size of 5 , was used to remove the

167 low-quality sequences via the Btrim program (Kong, 2011), and any sequences

168 containing N's or ambiguous bases were discarded. Only sequences from $245 \mathrm{bp}$ to $260 \mathrm{bp}$ in length for bacterium or $370 \mathrm{bp}$ to $400 \mathrm{bp}$ in length for archaea were treated as targeted sequences. The UPARSE program (Edgar, 2013) was used to remove chimeras and cluster sequences into $97 \%$ identical operational taxonomy units (OTUs) with singletons; the bacterium and archaea OTU tables were randomly resampled for the normalization of different sample reads. A representative sequence from each OTU was selected for taxonomic annotation

175 by comparison to the full SILVA 128 database (Quast et al., 2013). The Functional

176 Annotation of Prokaryotic Taxa (FAPROTAX) (Louca et al., 2016) was used to

177 convert the taxonomic microbial community profiles into putative functional

178 profiles based on the taxa identified in the sample; FAPROTAX defines functional

179 groups in terms of taxa (e.g., species or genera) affiliated with each functional 
180 group. These affiliations are mostly based on peer-reviewed literature, such as

181 announcements of cultured representatives.

183 Ecological and statistical analysis

184 The diversity indices (Shannon, Simpson and Observed Richness) for each

185 sample were calculated by the vegan package in $R$ software version $3.1 .3(R$

186 Development Core Team, 2012). Chao1 values were calculated using the Mothur

187 program (Schloss et al., 2009). The principal coordinate analysis (PCoA) was

188 generated using PyNAST (Caporaso et al., 2010), the FastTree program (Price et

189 al., 2009), and the UniFrac matrix (Lozupone and Knight, 2005; Lozupone et al.,

190 2006; Lozupone et al., 2007) from step-by-step analysis. The detrended

191 correspondence analysis (DCA) was generated by the vegan package in $\mathrm{R}$. The

192 statistical analysis was conducted by one-way analysis of variance (ANOVA) and

193 Tukey's test. A significance level of $p<0.05$ was adopted for all comparisons (He

194 and Wang, 2011).

\section{Results}

197 Sampling

198 Three hot springs from Niujie town were selected based on their different 199 depths. The temperatures ranged from $79^{\circ} \mathrm{C}$ to $82.5^{\circ} \mathrm{C}$, and the $\mathrm{pH}$ ranged from 2006.64 to 6.67 . According to the temperatures and $\mathrm{pH}$, there were no significant 201 differences between the samples. The environmental parameters data were 


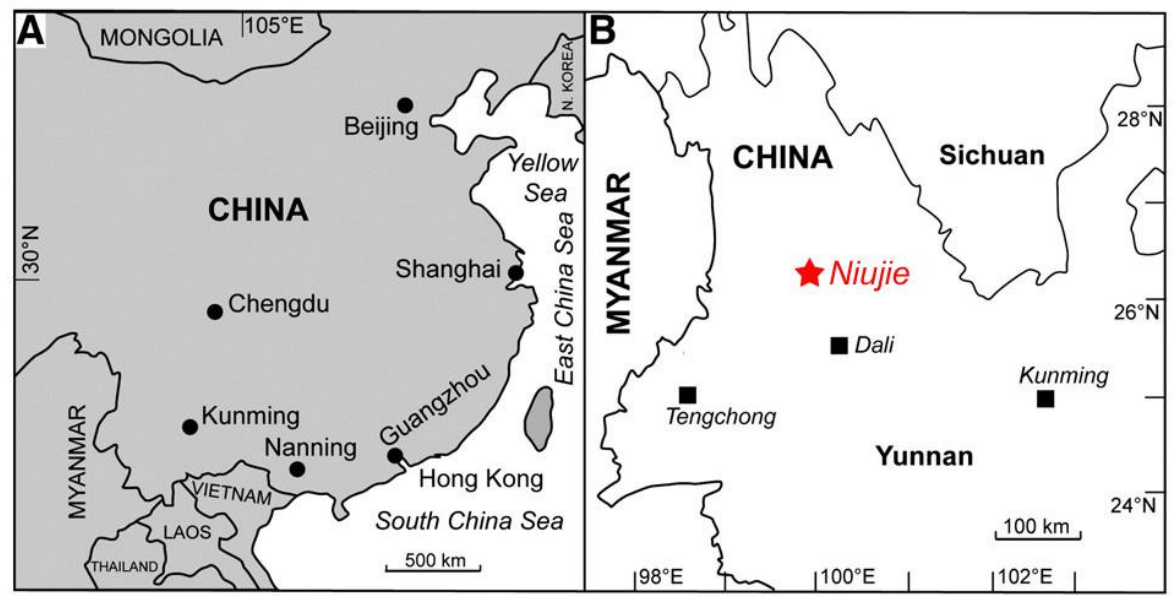

Fig 1. The geographical map showing the hot springs sampling locations in Niujie Town, Eryuan county, Dali city, Yunnan province, China.

Table 1. Sampling site parameters in this study.

\begin{tabular}{|c|c|c|c|c|c|}
\hline Sample ID & Latitude ${ }^{\circ} \mathrm{N}$ & Longitude ${ }^{\circ} \mathrm{E}$ & depth $(m)$ & Temperature ${ }^{\circ} \mathrm{C}$ & $\mathrm{pH}$ \\
\hline $0 \mathrm{~m}-1$ & $26^{\circ} 14^{\prime} 58.4514^{\prime \prime}$ & $99^{\circ} 59^{\prime} 32.604^{\prime \prime}$ & 0 & 79.0 & 6.64 \\
\hline $0 \mathrm{~m}-2$ & $26^{\circ} 14 ' 58.4514 "$ & $99^{\circ} 59^{\prime} 32.604 "$ & 0 & 79.0 & 6.64 \\
\hline $0 \mathrm{~m}-3$ & $26^{\circ} 14^{\prime} 58.4514^{\prime \prime}$ & $99^{\circ} 59^{\prime} 32.604 "$ & 0 & 79.0 & 6.64 \\
\hline $19 \mathrm{~m}-1$ & $26^{\circ} 14^{\prime} 58.3794 "$ & $99^{\circ} 59^{\prime} 29.58 "$ & 19 & 82.5 & 6.64 \\
\hline $19 \mathrm{~m}-2$ & $26^{\circ} 14^{\prime} 58.3794^{\prime \prime}$ & $99^{\circ} 59^{\prime} 29.58 "$ & 19 & 82.5 & 6.64 \\
\hline $19 \mathrm{~m}-3$ & $26^{\circ} 14^{\prime} 58.3794 "$ & $99^{\circ} 59^{\prime} 29.58 "$ & 19 & 82.5 & 6.64 \\
\hline $58 \mathrm{~m}-1$ & $26^{\circ} 15^{\prime} 0.324^{\prime \prime}$ & $99^{\circ} 59^{\prime} 27.132 "$ & 58 & 82.5 & 6.67 \\
\hline $58 \mathrm{~m}-2$ & $26^{\circ} 15^{\prime} 0.324^{\prime \prime}$ & $99^{\circ} 59^{\prime} 27.132 "$ & 58 & 82.5 & 6.67 \\
\hline $58 m-3$ & $26^{\circ} 15^{\prime} 0.324^{\prime \prime}$ & $99^{\circ} 59^{\prime} 27.132 "$ & 58 & 82.5 & 6.67 \\
\hline
\end{tabular}

210 Microbial diversity and community taxonomic composition 
213534875 sequences for bacterium and 111989 sequences for archaea were

214 clustered into 9 hot spring samples, and operational taxonomy unit tables were

215 generated for bacterium and archaea, respectively. For the microbial diversity, the

216 composition and structure of each sample could be compared; random

217 resampling was conducted for further analyses. The alpha diversity of the

218 microbial communities from different hot spring depths were calculated. The

219 Shannon and Inverse Simpson indexes indicated that the highest a-diversity was

220 observed in the $19 \mathrm{~m}$ samples for both bacterial and archaeal communities (Fig.

$2212)$.

222 The microbial community taxonomic composition was revealed at the 223 phylum/class and genus levels with a similarity of $97 \%$ for OTU classification.

224 After quality control and random resampling of the 9 samples, the sequence 225 reads were clustered into 4164 OTUs for bacteria at a $97 \%$ similarity level. The 226 bacterial groups at $0 \mathrm{~m}$ with the highest relative abundances at the phylum level 227 were members of Aquificae, Gamma-proteobacteria, and Deinococcus-Thermus.

228 For the $19 \mathrm{~m}$ sample, the dominant taxa were Alpha-proteobacteria, 229 Gamma-proteobacteria, and Firmicutes. The bacterial groups 230 Deinococcus-Thermus, Firmicutes, and Gamma-proteobacteria dominated in the $23158 \mathrm{~m}$ samples (Fig. 3A). At the genus level, the OTUs were distributed, with the 232 most abundant belonging to Hydrogenobacter and Thermus in hot spring samples 233 at $0 \mathrm{~m}$, while Sphingobium and Bacillus dominated in the hot spring samples at $23419 \mathrm{~m}$. In the hot spring samples at $58 \mathrm{~m}$, the most abundant belonged to Thermus 
$235(37.6 \%-59.3 \%)$ and Bacillus (Fig. 3B). For the archaeal communities, after 236 quality control and random resampling for the twelve samples, the sequence 237 reads were clustered into 43 OTUs for archaea at a $97 \%$ similarity level. 238 Thaumarchaeota was the most abundant phylum across all samples (Fig. 4A). At 239 the genus level, OTUs were distributed with the most abundant belonging to the 240 Uncultured Desulfurococcales archaeon in hot spring samples at $0 \mathrm{~m}$ and $58 \mathrm{~m}$. 241 In contrast, the most abundant belonged to Candidatus Nitrososphaera and 242 Ignisphaera in hot spring samples at $19 \mathrm{~m}$ (Fig. 4B). 


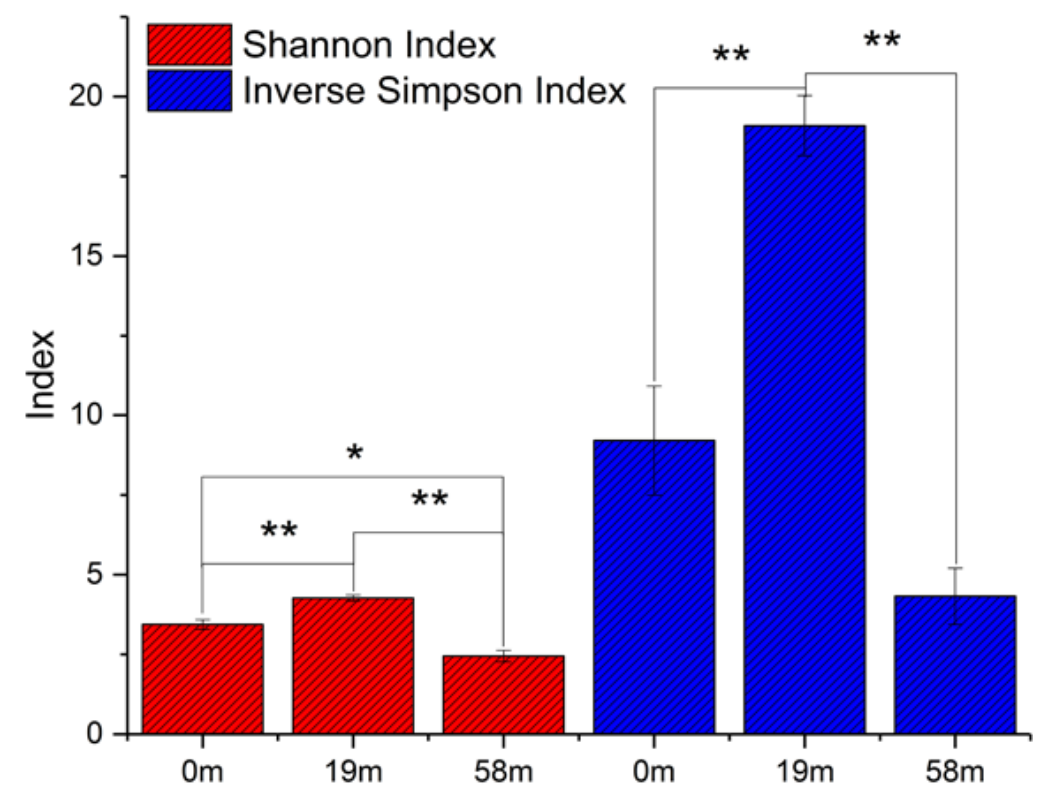

(A)

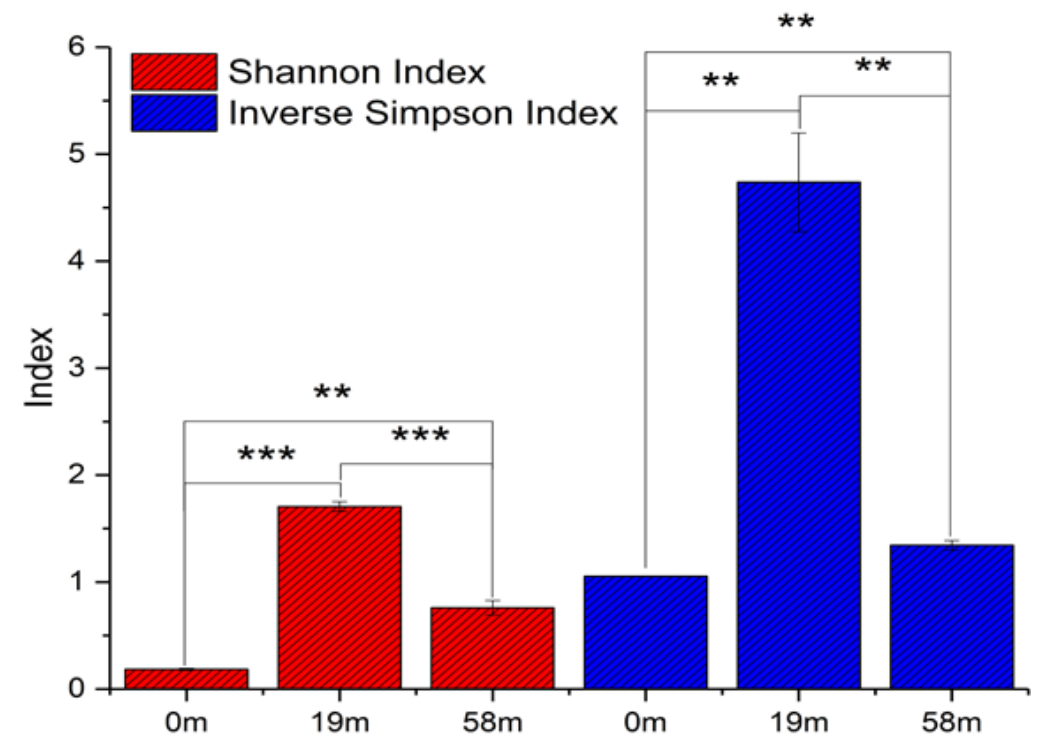

Fig 2. Comparison of the alpha diversity indexes, Shannon index and Inverse Simpson index (A: Bacterial communities; B: Archaeal communities). The value is the mean of the indices within each group. Error bars represent the standard error (SE). ${ }^{*} p<0.05$; 


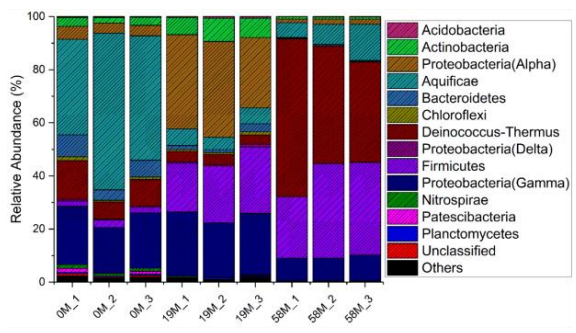

(A)

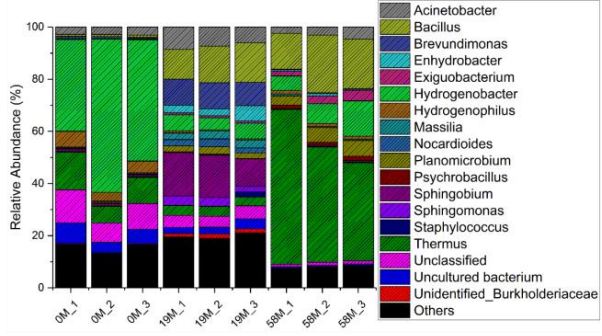

(B)

Fig 3. Stacked bar chart showing the relative abundance of the bacterial community composition at the phyla and classes of Proteobacteria level (A), and the genera level (B).

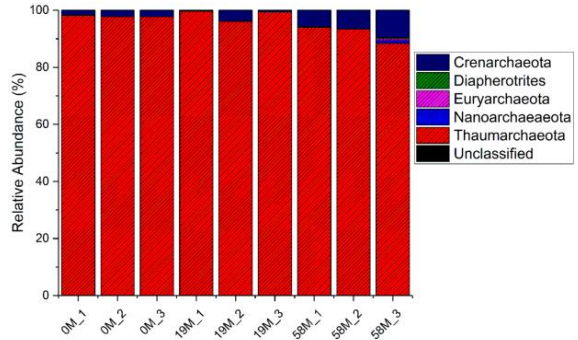

(A)

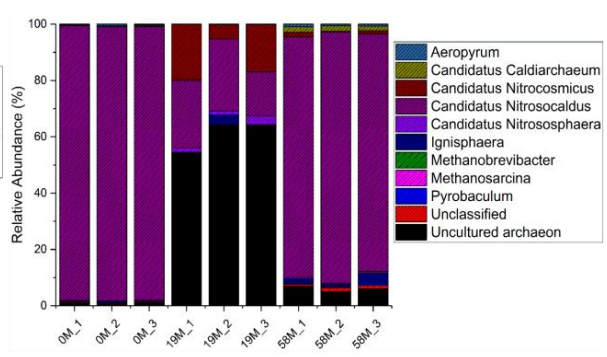

(B)

Fig 4. Stacked bar chart showing the relative abundance of the archaeal community composition at the phyla level (A), and the genera level (B).

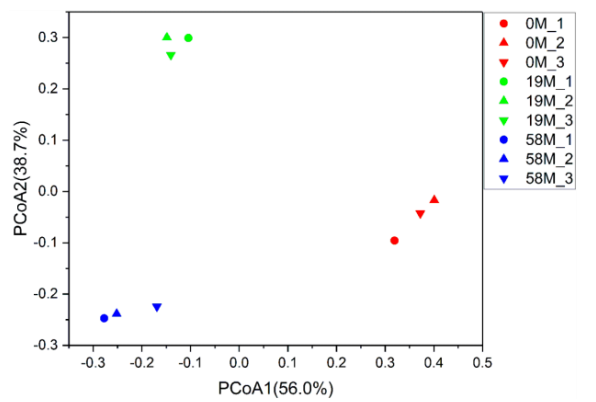

(A)

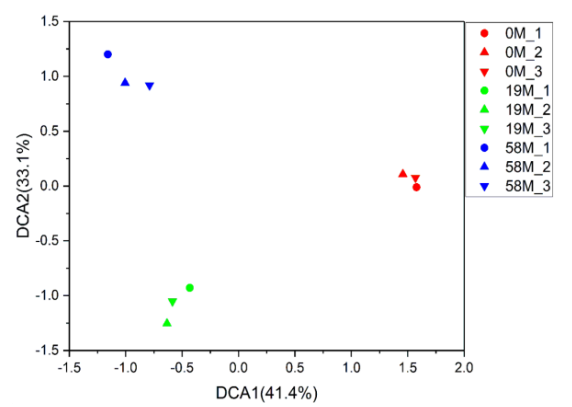

(B)

Fig 5. Principal coordinate analysis $(\mathrm{PCoA})$ of bacterial communities from hot springs at different depths (A). The results are based on weighted the UniFrac distances of the detected OTUs, and Detrended correspondence analysis (DCA) of bacterial communities from hot springs at different depths (B). The results are based on the detected OTUs. 


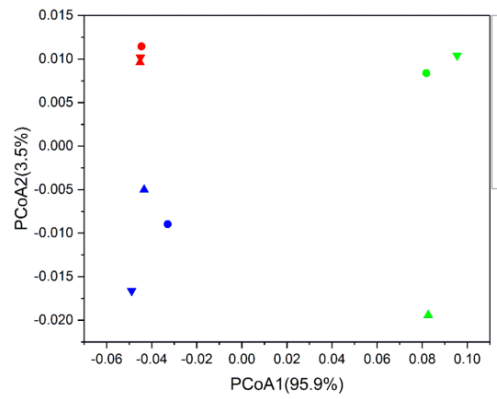

(A)

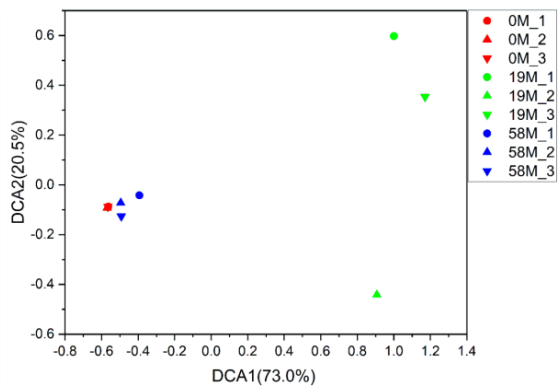

(B)

Fig 6. Principal coordinate analysis ( $\mathrm{PCoA})$ of archaeal communities from hot springs at different depths (A). The results based on the weighted UniFrac distances of the detected OTUs, and Detrended correspondence analysis (DCA) of archaeal communities from hot springs at different depths (B). The results are based on the detected OTUs.

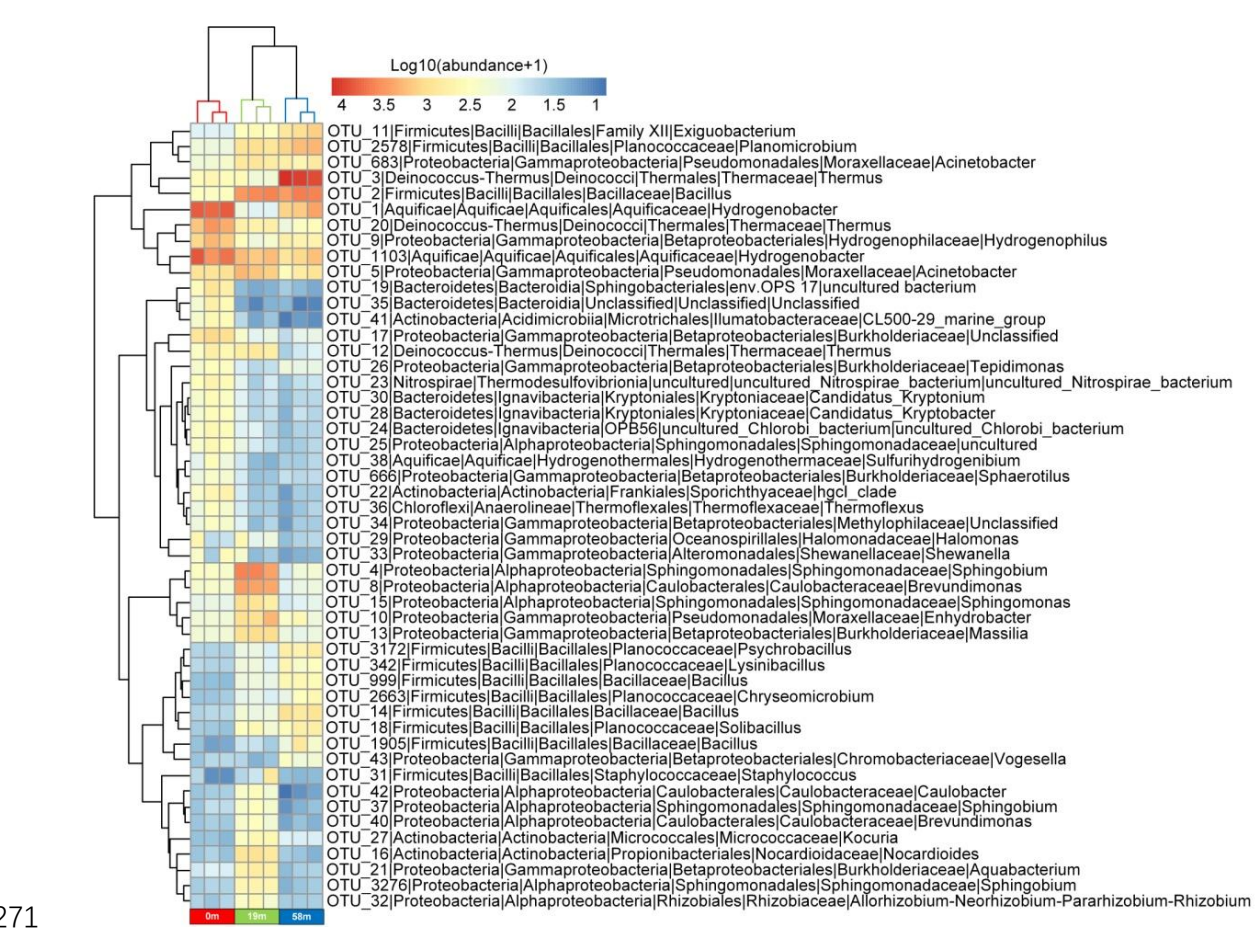

Fig 7. The 50 most abundant bacterial community OTUs from hot springs at different depths. Bacterial abundance was scaled with a log transformation in the heatmap. 


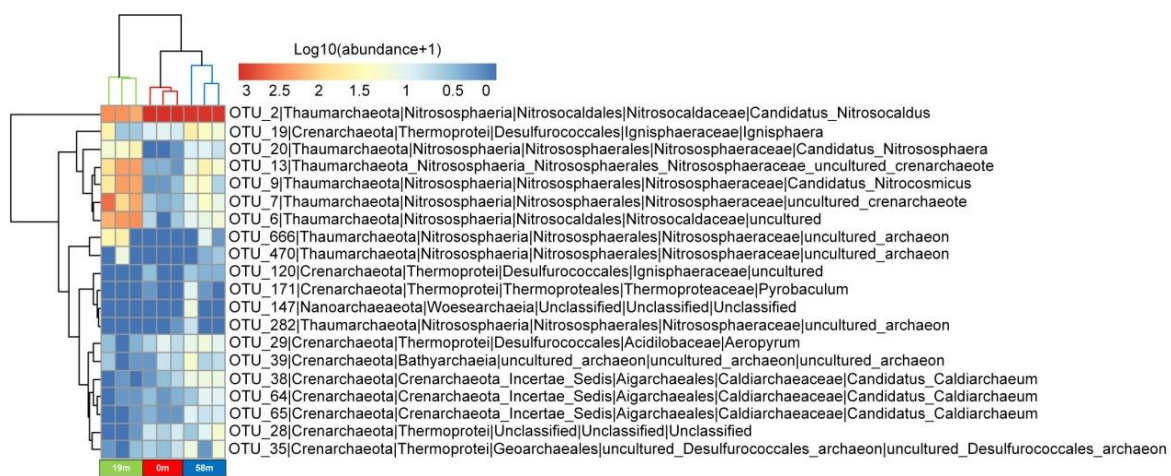

Fig 8. The 20 most abundant archaeal community OTUs from hot springs at different depths. Archaeal abundance was scaled with a log transformation in the heatmap.

Microbial community structure of hot springs at different depths

To examine the microbial community structure of the hot spring at different depths, ß-diversity-based statistical tools were applied, such as principal coordinate analysis (PCoA) and detrended correspondence analysis (DCA). Both PCoA and DCA showed that the bacterial community structures were distinctly separate from each group (Fig. 5), suggesting that there were differences in bacterial community structures of the hot spring at different depths. However, the archaeal community structure at $0 \mathrm{~m}$ and $58 \mathrm{~m}$ were similar, though they differed from the structure at $19 \mathrm{~m}$ (Fig. 6). A heatmap based on the 50 most abundant bacterial community OTUs and 20 most abundant archaeal community OTUs indicated different depths of hot springs could harbor distinct microbial communities (Fig. 7, 8).

Predictive functional profiling of bacterial and archaeal communities According to the FAPROTAX results based on the bacterial communities, 
294 the bacterium at $0 \mathrm{~m}$ are mainly involved in hydrogen, sulfur and thiosulfate

295 oxidation and nitrate reduction. The most frequent predicted function at $19 \mathrm{~m}$ and

$29658 \mathrm{~m}$ was chemoheterotrophy (Fig. 9). The FAPROTAX results based on the

297 archaeal communities showed that all the archaea are involved in ammonia

298 oxidation and nitrification (Fig. 10).

299

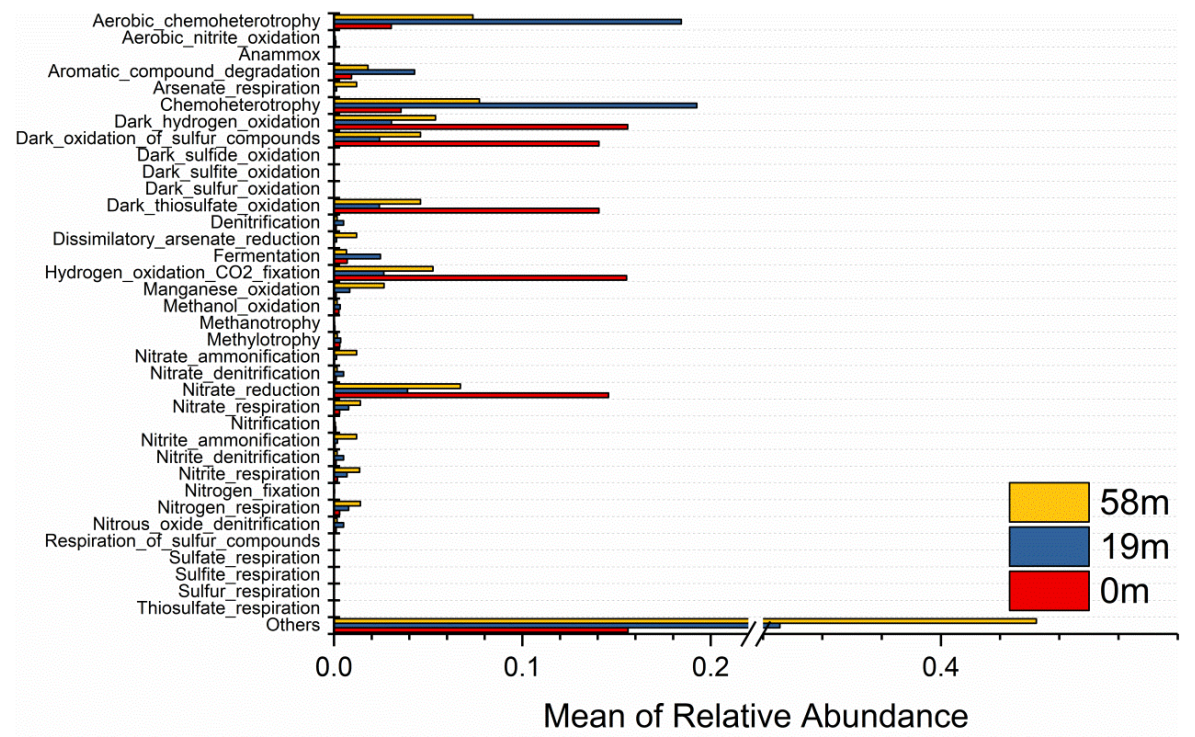

Fig 9. Stacked bar chart showing the mean relative abundance of the predicted metabolic potential of bacterium from hot springs at different depths, as predicted by FAPROTAX. 


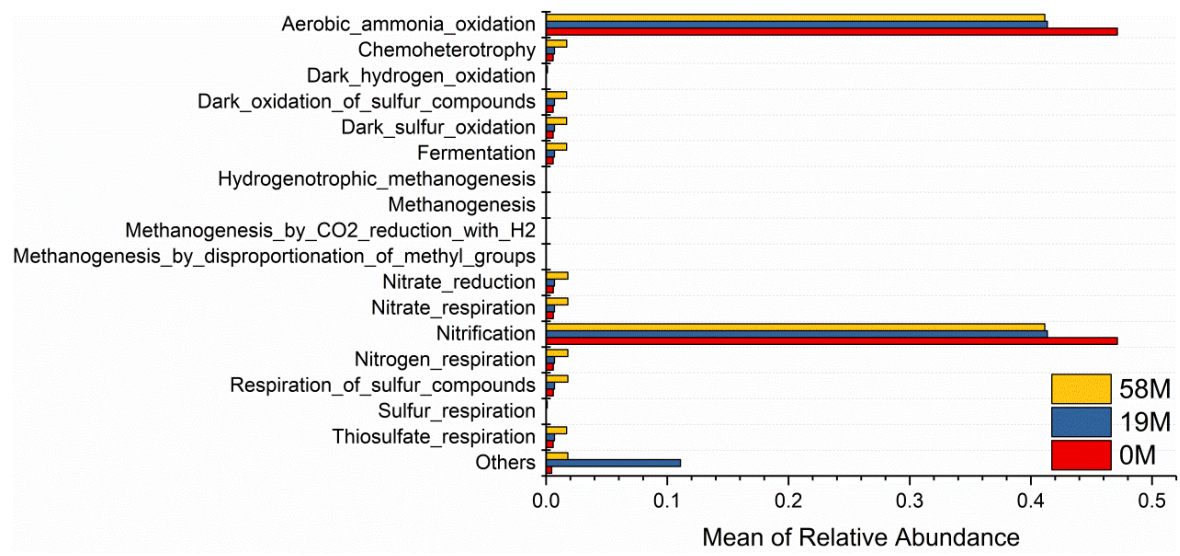

Fig 10. Stacked bar chart showing the mean of the relative abundance of the predicted metabolic potential of archaea from hot springs at different depths, as predicted by FAPROTAX.

Functional genes involved in the nitrogen, methane and sulfur cycle

Key functional genes for ammonification, nitrification, assimilatory $\mathrm{N}$ reduction, anammox, denitrification, and nitrogen fixation were detected in all samples. The functional genes involved in the nitrogen cycle at $58 \mathrm{~m}$ were the lowest among all samples (Fig. 11B). The heatmap results of functional genes involved in the nitrogen cycle showed that the functional structures of the microbial communities were similar at $19 \mathrm{~m}$ and $58 \mathrm{~m}$, but differed from that at 0 m (Fig. 11A). The signal intensity of genes involved in the methane cycle indicated that the metabolic potential for methane production or methanogenesis was very similar at all three hot springs depths (Fig. 12). For the functional genes involved in sulfur and sulfate metabolism, there were no significant differences between the samples at $0 \mathrm{~m}, 19 \mathrm{~m}$ and $58 \mathrm{~m}$ (Fig. 13B), though the functional gene structures of the sulfur and sulfate cycles showed some structural 


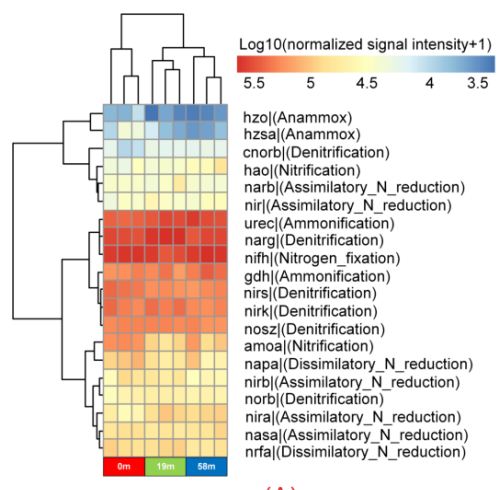

(A)

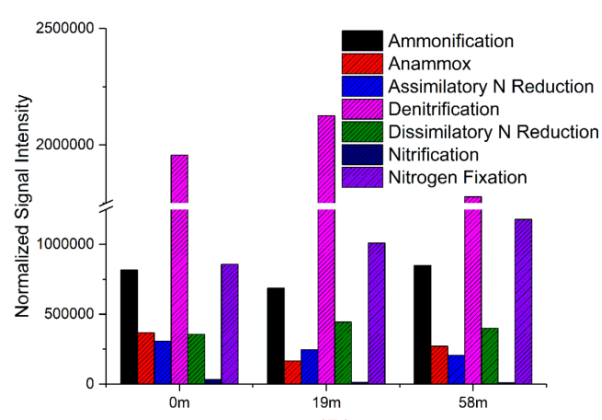

(B)

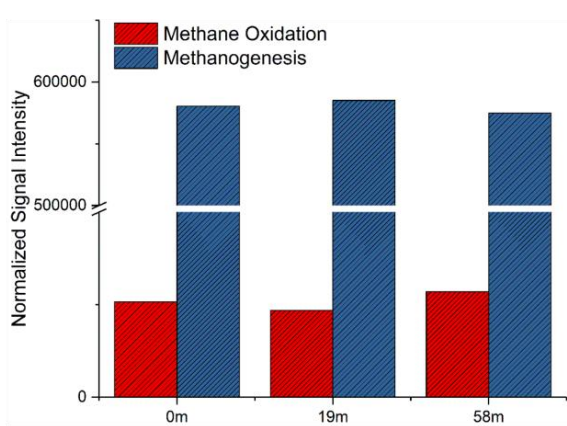

(B)

Fig. 12. The normalized signal intensity of the detected key genes involved in the methane cycle (A). The signal intensity for each functional gene category is the average of the total signal intensity from all the replicates, and the heatmap of the functional genes involved in the methane cycle at different hot springs depths (B). 


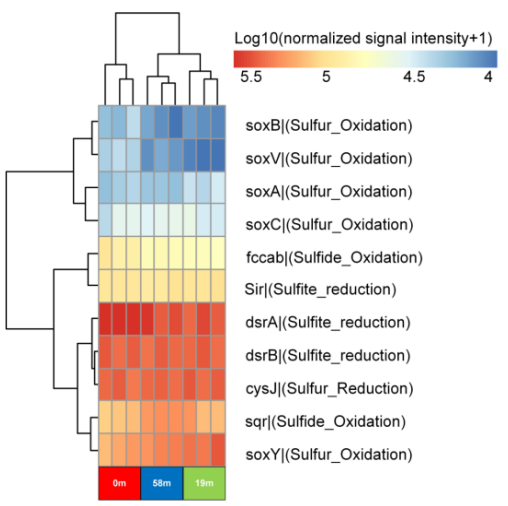

(A)

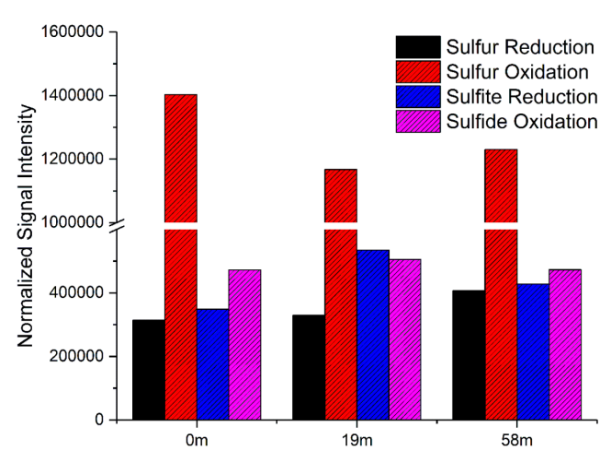

(B)

Fig. 13. The normalized signal intensity of the detected key genes involved in the sulfur cycle (A). The signal intensity for each functional gene category is the average of the total signal intensity from all the replicates, and the heatmap of functional genes involved in the sulfur cycle at different hot springs depths (B).

\section{Discussion}

To better understand the diversity of life on Earth, especially the evolution and potential origin of life (Des Marais and Walter. 2019), intensive study of intraterrestrial microbes from harsh condition environments and the mechanism of how microorganisms tolerate extreme environmental conditions should not be ignored (Fredrickson and Balkwill. 2006). The diversity of archaea and bacteria in hot springs, an extreme environment, has been investigated extensively. However, most of the research has been focused on the surface of hot springs (Wang et al., 2013; Li et al., 2015; Chen et al., 2016; Bowen De León et al., 2013; Menzel et al., 2015; Rozanov et al., 2014; Kambura et al., 2016; Saxena et al., 2017; Tang et al., 2018). To date, not many studies have attempted a direct comparison of microbe composition and functions at different depths of hot springs. In this study, we investigated the microbial and functional gene diversity at different depths of 
357 hot springs in Niujie town, Yunnan province, China. The research area was an

358 ideal study site for research on hot springs at different depths. We characterized

359 the bacterial and archaeal communities in neutral ( $\mathrm{pH} 6.64-6.72$ )

360 high-temperature $\left(79^{\circ} \mathrm{C}-83^{\circ} \mathrm{C}\right)$ hot springs. Although the environmental

361 parameters were similar, the bacteria datasets demonstrated a general shift from

362 Aquificae at $0 \mathrm{~m}$ to Proteobacteria and Firmicutes at $19 \mathrm{~m}$, with an additional shift

363 to Deinococcus-Thermus and Firmicutes at $58 \mathrm{~m}$. At the genus level, the

364 dominant species were different at different depths of hot spring water, with

365 Hydrogenobacter being the most dominant among the $0 \mathrm{~m}$ samples. By

366 increasing the depth to $19 \mathrm{~m}$, the dominant species observed were Sphingobium

367 and Bacillus, whereas Thermus and Bacillus dominated the hot spring at $58 \mathrm{~m}$.

368 DCA and PCoA also showed that the bacterial communities were different at

369 different depths. Previously, Hou et al. showed that Hydrogenobacter and

370 Aquificae were the dominant genus and phylum, respectively, in neutral and

371 alkaline high-temperature surface hot springs in Tengchong, Yunnan Province,

372 China. Our bacterial community results at $0 \mathrm{~m}$ were consistent with the results of

373 Hou et al. Ferrous iron $\left(\mathrm{Fe}^{2+}\right)$, thiosulfate $\left(\mathrm{S}_{2} \mathrm{O}_{3}{ }^{2-}\right)$, elemental sulfur ( $\left.\mathrm{S}^{0}\right)$, hydrogen

374 sulfide $\left(\mathrm{H}_{2} \mathrm{~S}\right)$, and hydrogen $\left(\mathrm{H}_{2}\right)$ are very common inorganic electron donors in

375 hydrothermal environments (Amend and Shock., 2001; Shock et al., 2010). In

376 oxidation-reduction reactions, the oxidation of $\mathrm{H}_{2}$ is generally coupled with the

377 reduction of oxygen $\left(\mathrm{O}_{2}\right)$, nitrate $\left(\mathrm{NO}_{3}{ }^{-}\right)$, $\mathrm{S} 0$, sulfate $\left(\mathrm{SO}_{4}{ }^{2-}\right), \mathrm{S}_{2} \mathrm{O}_{3}{ }^{2-}$, or ferric iron

$378\left(\mathrm{Fe}^{3+}\right)$ (Shock et al., 2010; Spear et al., 2005). The bacterial community results 
379 showed that Hydrogenobacter from Aquificae can be detected at all three hot

380 springs depths, and functional profiling of the bacterial communities revealed the

381 bacteria in the hot springs are involved in hydrogen, sulfur and thiosulfate oxidation and nitrate reduction, especially at $0 \mathrm{~m}$. This finding supports work

383 focused on inorganic sources of oxidation and microbial metabolism in

384 environments with high temperatures (Lindsay et al., 2018). Surprisingly,

385 Sphingobium and Bacillus dominated the hot spring at $19 \mathrm{~m}$. As is known, microbes in hot springs can produce thermostable enzymes, which is one reason

387 that thermophilic microbes can tolerate harsh conditions, such as high 388 temperature (Chalopagorn et al., 2014). Thermus aquaticus is a classic example 389 that produces Taq DNA polymerase (Chien et al., 1976). Another example is a

390 Bacillus strain isolated from a hot spring in Kalianda Island. Its lipase gene lip256

391 was cloned and expressed; Lip256 exhibited high activity at high temperatures, 392 with $40 \%$ maximum activity at $80{ }^{\circ} \mathrm{C}$ and good stability at temperatures ranging 393 from 50 to $80^{\circ} \mathrm{C}$ (Li and Liu. 2017). Sphingobium, which is capable of degrading 394 hydrocarbons, are very common microorganisms in oil-contaminated 395 environments (Chaudhary et al., 2017; Park et al., 2019), but they are very rarely 396 found in hot springs environments. This finding was unexpected and this result 397 may be explained by the fact that the hot spring well was just completed; the 398 drilling equipment was still present and may have leaked some oil into the ground.

399 Not only that, the main predicted functions at $19 \mathrm{~m}$ were chemoheterotrophy and 400 aromatic compound degradation, which indicated that the bacteria at $19 \mathrm{~m}$ were 
401 involved in the hydrocarbon cycle. The phylum Deinococcus-Thermus is divided

402 into the orders Deinococcales and Thermales. Thermus, which dominated the 403 samples at $58 \mathrm{~m}$, belongs to the order Thermales. Previous reports found that 404 Thermus was only detected in specific areas, such as the Gongxiaoshe hot spring 405 in Ruidian, Yunnan province, China. Another interesting fact is that Thermus in 406 China differed from that from a Yellowstone hot springs (Song et al., 2013). The $407 \mathrm{pH}$ and temperature of the Gongxiaoshe hot spring in Ruidian were 7.3 and $40873.8{ }^{\circ} \mathrm{C}$, respectively (Hou et al., 2013), which are consistent with previous 409 results for the neutral and alkaline hot springs in Yellowstone where Thermus, 410 which generally requires an optimum temperature of approximately $70^{\circ} \mathrm{C}-75^{\circ} \mathrm{C}$ 411 (da Costa et al., 2006), was found. However, in our results, Thermus dominated 412 the $82{ }^{\circ} \mathrm{C}$ hot spring at the $58 \mathrm{~m}$ depth, which may expand our understanding of 413 the growth temperature of Thermus.

414 Previous studies have suggested that archaea are very rare in neutral and 415 alkaline hot springs (Reysenbach et al., 1994; Hugenholtz et al., 1998; Inskeep et 416 al., 2010). However, studies have also shown that bacterium and archaea can 417 ubiquitously coexist in nonacid hot springs (Schouten et al., 2007; Bowen De 418 León et al., 2013). In our studies, Thaumarchaeota was the dominant phylum in 419 the neutral high-temperature hot spring, and the majority of archaeal sequences 420 in this hot spring were related to "Candidatus_Nitrosocaldus", a putative 421 ammonia-oxidizing archaeon (Hou et al., 2013; Bowen De León et al., 2013). Our 422 archaeal community results at $0 \mathrm{~m}, 19 \mathrm{~m}$, and $58 \mathrm{~m}$ were consistent with previous 
423 results. Based on the cultivation and characterization of 'Candidatus

424 Nitrosocaldus yellowstonii', Candidatus Nitrosocaldus was thought to be involved

425 in ammonia oxidation (de la Torre et al., 2008; Nishizawa et al., 2016). Our

426 predictive functional profiling of archaeal communities and functional gene array

427 results indicated the potentially important role for nitrogen cycling in the neutral

428 high-temperature hot spring, both at the surface or at the varying depths.

429 Prior studies have noted the importance of methanogenesis in the early 430 Archaean era (Ueno et al., 2006). Many methanogens are encountered in

431 thermophilic or hyperthermophilic hydrothermal vents and form the lower roots of 432 the evolutionary tree, providing the hypothesis that life on earth originated in 433 thermal environments with energy conserved by methanogenesis (Russell and 434 Nitschke. 2017). Therefore, methane cycling in the hot spring environments 435 should be noticed. However, in our results, we did not find intense biotic methane 436 metabolic processes, such as methanogenesis or methane oxidation. Most 437 methanogenesis is derived from microorganisms affiliated with Euryarchaeota 438 (McKay et al., 2019), though some microbes from Bathyarchaeota (Evans et al., 439 2015) and Verstraetearchaeota (Vanwonterghem et al., 2016) were recently found 440 to be involved in methanogenesis. According to our archaeal community results, 441 we only detected a few Methanosarcina and Methanobrevibacter species, which 442 are affiliated with Euryarchaeota, at $19 \mathrm{~m}$ and $50 \mathrm{~m}$. Some methane-oxidizing 443 bacterium, such as Methylomonas, Methylocaldum, Methylobacter, 444 Methylothermus, and Methylocystis were found in our bacteria datasets but they 
445 mostly belong to minor groups.

446 In summary, three different depths in a neutral $(\mathrm{pH} 6.64-6.72)$

447 high-temperature $\left(79^{\circ} \mathrm{C}-83^{\circ} \mathrm{C}\right)$ hot springs were investigated by $16 \mathrm{~S}$ rRNA gene

448 high-throughput sequencing and GeoChip functional gene microarray. Our results

449 revealed that the bacterial communities were different at different depths. Our

450 results showed that the microbial diversity and composition shifted at different

451 depths in a very small area and that the microbes at different hot springs depths

452 are mainly involved the following processes: hydrogen, sulfur and thiosulfate

453 oxidation; nitrate reduction; ammonia oxidation; and nitrification. Our study not

454 only provides comprehensive insights into the microbial community at the

455 different depths in hot springs but also provides new insights into the

456 deep-subsurface biosphere associated with terrestrial hot springs.

457

458

459

460

461

462

463

464

465

466

467

468

469

Acknowledgments

Thanks to the editor and the reviewers for their constructive comments. This study was financially supported by the National Natural Science Foundation of China (Grant No. 41602345 and 41506139).

\section{References}

Amann, R.I., Ludwig, W., Schleifer, K.H.: Phylogenetic identification and in situ detection of individual microbial cells without cultivation, Microbiol. Rev., 59(1), 143-169, 1995.

Amend, J.P., Shock, E.L.: Energetics of overall metabolic reactions of thermophilic and hyperthermophilic Archaea and bacteria, FEMS. Microbiol. Rev., 25(2), 175-243, 2001. 
Bai, S., Li, J., He, Z., Van, Nostrand, J.D., Tian, Y., Lin, G., Zhou, J., Zheng, T.: GeoChip-based analysis of the functional gene diversity and metabolic potential of soil microbial communities of mangroves, Appl. Microbiol. Biotechnol., 97(15), 7035-7048, 2013.

Bowen De León, K., Gerlach, R., Peyton, B.M., Fields, M.W.: Archaeal and bacterial communities in three alkaline hot springs in Heart Lake Geyser Basin, Yellowstone National Park, Front. Microbiol., 4, 330, 2013.

Caporaso, J.G., Bittinger, K., Bushman, F.D., DeSantis, T.Z., Andersen, G.L., Knight, R.: PyNAST: a flexible tool for aligning sequences to a template alignment, Bioinformatics., 26(2), 266-267, 2010.

Chalopagorn, P., Charoenpanich, J., Choowongkomon, K.: Genome shuffling enhances lipase production of thermophilic Geobacillus sp, Appl. Biochem. Biotechnol., 174(4), 1444-1454, 2014.

Chaudhary, D.K., Jeong, S.W., Kim, J.: Sphingobium naphthae sp. nov., with the ability to degrade aliphatic hydrocarbons, isolated from oil-contaminated soil, Int. J. Syst. Evol. Microbiol., 67(8), 2986-2993, 2017.

Chen, S., Peng, X., Xu, H., Ta, K.: Composition of ammonia-oxidizingarchaea and their contribution to nitrification in a high-temperature hotspring, Biogeosciences., 13(1), 2051-2060, 2016.

Chien, A., Edgar, D.B., Trela, J.M.: Deoxyribonucleic acid polymerase from the extreme thermophile Thermus aquaticus, J. Bacteriol., 127(3), 1550-1557, 1976.

Colin, Y., O, Nicolitch., J.D., Van, Nostrand., J.Z., Zhou., M.P., Turpault., S, Uroz.: Taxonomic and functional shifts in the beech rhizosphere microbiome across a natural soil toposequence, Sci. Rep., 7, 9604, 2017.

da Costa, M.S., Rainey, F.A., Nobre, M.F.: The genus Thermus and relatives, In book: The Prokaryotes., pp:797-812.doi:10.1007/0-387-30747-8_32, 2006.

de la Torre, J.R., Walker, C.B., Ingalls, A.E., Könneke, M., Stahl, D.A.: Cultivation of a thermophilic ammonia oxidizing archaeon synthesizing crenarchaeol, Environ. Microbiol., 10(3), 810-818, 2008.

Des Marais, D.J., Walter, M.R.: Terrestrial Hot Spring Systems: Introduction, Astrobiology., doi: 10.1089/ast.2018, 1976, 2019.

Edgar, R.C.: UPARSE: highly accurate OTU sequences from microbial amplicon reads, Nat. Methods., 10(10), 996-998, 2013. 
https://doi.org/10.5194/bg-2019-406

Preprint. Discussion started: 10 December 2019

(c) Author(s) 2019. CC BY 4.0 License.

Evans, P.N., Parks, D.H., Chadwick, G.L., Robbins, S.J., Orphan, V.J., Golding, S.D., Tyson, G.W.: Methane metabolism in the archaeal phylum Bathyarchaeota revealed by genome-centric metagenomics, Science, 350(6259), 434-438, 2015.

Fredrickson, J.K., Balkwill, D.L.: Geomicrobiological processes and biodiversity in the deep terrestrial subsurface, Geomicrobiol. J., 23(6), 345-356, 2006.

Ghosh D, Bal B, Kashyap VK, Pal S (2003) Molecular phylogenetic exploration of bacterial diversity in a Bakreshwar (India) hot spring and culture of Shewanella-related thermophiles. Appl Environ Microbiol 69(7):4332-4336.

Gold, T.: The deep, hot biosphere, Proc. Natl. Acad. Sci. U S A., 89(13), 6045-6049, 1992.

He, M., Wang, W.X.: Factors affecting the bioaccessibility of methylmercury in several marine fish species, J. Agric. Food. Chem., 59(13), 7155-7162, 2011.

Huang, Q., Jiang, H., Briggs, B.R., Wang, S., Hou, W., Li, G., Wu, G., Solis, R., Arcilla, C.A., Abrajano, T., Dong, H.: Archaeal and bacterial diversity in acidic to circumneutral hot springs in the Philippines, FEMS. Microbiol. Ecol., 85(3), 452-464, 2013.

Hugenholtz, P., Pitulle, C., Hershberger, K.L., Pace, N.R.: Novel division level bacterial diversity in a Yellowstone hot spring, J. Bacteriol., 180(2), 366-376, 1998.

Hou, W., Wang, S., Dong, H., Jiang, H., Briggs, B.R., Peacock, J.P., Huang, Q., Huang, L., Wu, G., Zhi, X., Li, W., Dodsworth, J.A., Hedlund, B.P., Zhang, C., Hartnett, H.E., Dijkstra, P., Hungate, B.A.: A comprehensive census of microbial diversity in hot springs of Tengchong, Yunnan Province China using 16S rRNA gene pyrosequencing, PLoS. One., 8(1), e53350, 2013.

Inskeep, W.P., Rusch, D.B., Jay, Z.J., Herrgard, M.J., Kozubal, M.A., Richardson, T.H., Macur, R.E., Hamamura, N., Jennings, R.d., Fouke, B.W., Reysenbach, A.L., Roberto, F., Young, M., Schwartz, A., Boyd, E.S., Badger, J.H., Mathur, E.J., Ortmann, A.C., Bateson, M., Geesey, G., Frazier, M.: Metagenomes from high-temperature chemotrophic systems reveal geochemical controls on microbial community structure and function, PLoS. One., 5(3), e9773, 2010.

Kambura, A.K., Mwirichia, R.K., Kasili, R.W., Karanja, E.N., Makonde, H.M., Boga, H.I.: Bacteria and Archaea diversity within the hot springs of Lake Magadi and Little Magadi in Kenya, BMC. Microbiol., 16(1), 136, 2016.

Kearey, P., Wei, H.: Geothermal fields of China, J. Volcanol. Geotherm. Res., 56, 415-428, 1993.

Kong, Y.: Btrim: a fast, lightweight adapter and quality trimming program for next-generation 
https://doi.org/10.5194/bg-2019-406

Preprint. Discussion started: 10 December 2019

(c) Author(s) 2019. CC BY 4.0 License.

sequencing technologies, Genomics., 98(2), 152-153, 2011.

Li, J., Peng, X., Zhang, L., Jiang, L., Chen, S.: Linking microbial community structure to S, N and Fe biogeochemical cycling in the hot springs at the Tengchong geothermal fields, Southwest China, Geomicrobiology. J., 32(11), 1-15, 2015.

Li, J., Liu, X.: Identification and Characterization of a Novel Thermophilic, Organic Solvent Stable Lipase of Bacillus from a Hot Spring, Lipids., 52(7), 619-627, 2017.

Lindsay, M.R., Amenabar, M.J., Fecteau, K.M., Debes, R.V. 2nd., Fernandes Martins, M.C., Fristad, K.E., Xu, H., Hoehler, T.M., Shock, E.L., Boyd, E.S.: Subsurface processes influence oxidant availability and chemoautotrophic hydrogen metabolism in Yellowstone hot springs, Geobiology., 16(6), 674-692, 2018.

Louca, S., Parfrey, L.W., Doebeli, M.: Decoupling function and taxonomy in the global ocean microbiome, Science., 353(6305), 1272-1277, 2016.

Lozupone, C., Knight, R.: UniFrac: a new phylogenetic method for comparing microbial communities, Appl. Environ. Microbiol., 71(12), 8228-8235, 2005.

Lozupone, C., Hamady, M., Knight, R.: UniFrac--an online tool for comparing microbial community diversity in a phylogenetic context, BMC. Bioinformatics., 7, 371, 2006.

Lozupone, C.A., Hamady, M., Kelley, S.T., Knight, R.: Quantitative and qualitative beta diversity measures lead to different insights into factors that structure microbial communities, Appl. Environ. Microbiol., 73(5), 1576-1585, 2007.

Ma, X., Zhao, C., Gao, Y., Liu, B., Wang, T., Yuan, T., Hale, L., Nostrand, J.D.V., Wan, S., Zhou, J., Yang, Y.: Divergent taxonomic and functional responses of microbial communities to field simulation of aeolian soil erosion and deposition, Mol. Ecol., 26(16), 4186-4196, 2017.

Magoč, T., Salzberg, S.L.: FLASH: fast length adjustment of short reads to improve genome assemblies, Bioinformatics., 27(21), 2957-2963, 2011.

Marsh, C.L., Larsen, D.H.: Characterization of some thermophilic bacteria from the hot springs of Yellowstone National Park, J. Bacteriol., 65(2), 193-197, 1953.

McKay, L.J., Dlakić, M., Fields, M.W., Delmont, T.O., Eren, A.M., Jay, Z.J., Klingelsmith, K.B., Rusch, D.B., Inskeep, W.P.: Co-occurring genomic capacity for anaerobic methane and dissimilatory sulfur metabolisms discovered in the Korarchaeota, Nat. Microbiol., 4(4), 614-622, 2019.

Menzel, P., Gudbergsdóttir, S.R., Rike, A.G., Lin, L., Zhang, Q., Contursi, P., Moracci, M., Kristjansson, J.K., Bolduc, B., Gavrilov, S., Ravin, N., Mardanov, A., Bonch-Osmolovskaya, E., 
https://doi.org/10.5194/bg-2019-406

Preprint. Discussion started: 10 December 2019

(c) Author(s) 2019. CC BY 4.0 License.

Young, M., Krogh, A., Peng, X.: Comparative Metagenomics of Eight Geographically Remote Terrestrial Hot Springs, Microb. Ecol., 70(2), 411-424, 2015.

Mirete, S., Morgante, V,, González-Pastor, J.E.: Functional metagenomics of extreme environments, Curr. Opin. Biotechnol., 38, 143-149, 2016.

Nishizawa, M., Sakai, S., Konno, U., Nakahara, N., Takaki, Y., Saito, Y., Imachi, H., Tasumi, E., Makabe, A., Koba, K., Takai, K.: Nitrogen and Oxygen Isotope Effects of Ammonia Oxidation by Thermophilic Thaumarchaeota from a Geothermal Water Stream, Appl. Environ. Microbiol., 82(15), 4492-4504, 2016.

Park, Y.J., Kim, K.H., Han, D.M., Lee, D.H., Jeon, C.O.: Sphingobium terrigena sp. nov., isolated from gasoline-contaminated soil, Int. J. Syst. Evol. Microbiol., 69(8), 2459-2464, 2019.

Price, M.N., Dehal, P.S., Arkin, A.P.: FastTree: computing large minimum evolution trees with profiles instead of a distance matrix, Mol. Biol. Evol., 26(7), 1641-1650, 2009.

Quast, C., Pruesse, E., Yilmaz, P., Gerken, J., Schweer, T., Yarza, P., Peplies, J., Glöckner, F.O.: The SILVA ribosomal RNA gene database project: improved data processing and web-based tools, Nucleic. Acids. Res., 41(Database issue), D590-596, 2013.

R Development Core Team.: R: A Language and Environment for Statistical Computing. Vienna, Austria : the R Foundation for Statistical Computing, ISBN: 3-900051-07-0, Available online at http://www.R-project.org/, 2012.

Reysenbach, A.L., Wickham, G.S., Pace, N.R.: Phylogenetic analysis of the hyperthermophilic pink filament community in Octopus Spring, Yellowstone National Park, Appl. Environ. Microbiol., 60(6), 2113-2119, 1994.

Rozanov, A.S., Bryanskaya, A.V., Malup, T.K., Meshcheryakova, I.A., Lazareva, E.V., Taran, O.P., Ivanisenko, T.V., Ivanisenko, V.A., Zhmodik, S.M., Kolchanov, N.A., Peltek, S.E.: Molecular analysis of the benthos microbial community in Zavarzin thermal spring (Uzon Caldera, Kamchatka, Russia), BMC. Genomics., 15(Suppl 12), S12, 2014.

Russell, M.J., Nitschke, W.: Methane: Fuel or Exhaust at the Emergence of Life?, Astrobiology., 17(10), 1053-1066, 2017.

Saxena., R., Dhakan, D.B., Mittal, P., Waiker, P., Chowdhury, A., Ghatak, A., Sharma, V.K.: Metagenomic Analysis of Hot Springs in Central India Reveals Hydrocarbon Degrading Thermophiles and Pathways Essential for Survival in Extreme Environments, Front. Microbiol., 7, 2123, 2017.

Schloss, P.D., Westcott, S.L., Ryabin, T., Hall, J.R., Hartmann, M., Hollister, E.B., Lesniewski, R.A., Oakley, B.B., Parks, D.H., Robinson, C.J., Sahl, J.W., Stres, B., Thallinger, G.G., Van 
Horn, D.J., Weber, C.F.: Introducing mothur: open-source, platform-independent, community-supported software for describing and comparing microbial communities, Appl. Environ. Microbiol., 75(23), 7537-7541, 2009.

Schouten, S., van der Meer, M.T., Hopmans, E.C., Rijpstra, W.I., Reysenbach, A.L., Ward, D.M., Sinninghe Damsté, J.S.: Archaeal and bacterial glycerol dialkyl glycerol tetraether lipids in hot springs of yellowstone national park, Appl. Environ. Microbiol., 73(19), 6181-6191, 2007.

Shock, E.L., Holland, M., Meyer-Dombard, D.A., Amend, J.P., Osburn, G.R., Fischer, T.P.: Quantifying inorganic sources of geochemical energy in hydrothermal ecosystems, Yellowstone National Park, USA, Geochimica. et. Cosmochimica. Acta., 74(14), 4005-4043, 2010.

Shi, Z., Yin, H., Van Nostrand, J.D., Voordeckers, J.W., Tu, Q., Deng, Y., Yuan, M., Zhou, A., Zhang, P., Xiao, N., Ning, D., He, Z., Wu, L., Zhou, J.: Functional Gene Array-Based Ultrasensitive and Quantitative Detection of Microbial Populations in Complex Communities, mSystems., 4(4), e00296-19, 2019.

Song, Z.Q., Wang, F.P., Zhi, X.Y., Chen, J.Q., Zhou, E.M., Liang, F., Xiao, X., Tang, S.K., Jiang, H.C., Zhang, C.L., Dong, H., Li, W.J.: Bacterial and archaeal diversities in Yunnan and Tibetan hot springs, China, Environ. Microbiol., 15(4), 1160-1175, 2013.

Spear, J.R., Walker, J.J., McCollom, T.M., Pace, N.R.: Hydrogen and bioenergetics in the Yellowstone geothermal ecosystem, Proc. Natl. Acad. Sci. U S A., 102(7), 2555-2560, 2005.

Tang, J., Liang, Y., Jiang, D., Li, L., Luo, Y., Shah, M.M.R., Daroch, M.: Temperature-controlled thermophilic bacterial communities in hot springs of western Sichuan, China, BMC. Microbiol., 18(1), 134, 2018.

Ueno, Y., Yamada, K., Yoshida, N., Maruyama, S., Isozaki, Y.: Evidence from fluid inclusions for microbial methanogenesis in the early Archaean era, Nature., 440(7083), 516-519, 2006.

Vanwonterghem, I., Evans, P.N., Parks, D.H., Jensen, P.D., Woodcroft, B.J., Hugenholtz, P., Tyson, G.W.: Methylotrophic methanogenesis discovered in the archaeal phylum Verstraetearchaeota, Nat. Microbiol., 1, 16170, 2016.

Wang, S., Hou, W., Dong, H., Jiang, H., Huang, L., Wu, G., Zhang, C., Song, Z., Zhang, Y., Ren, H., Zhang, J., Zhang, L.: Control of temperature on microbial community structure in hot springs of the Tibetan Plateau, PLoS. One., 8(5), e62901, 2013.

Wu, L., Liu, X., Schadt, C.W., Zhou, J.: Microarray-based analysis of subnanogram quantities of microbial community DNAs by using whole-community genome amplification, Appl. Environ. Microbiol., 72(7), 4931-4941, 2006.

Zhao, M., Xue, K., Wang, F., Liu, S., Bai, S., Sun, B., Zhou, J., Yang, Y.: Microbial mediation of 
https://doi.org/10.5194/bg-2019-406

Preprint. Discussion started: 10 December 2019

(c) Author(s) 2019. CC BY 4.0 License.

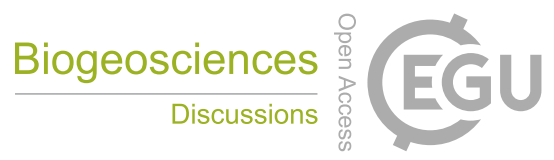

(c) (1)

690 biogeochemical cycles revealed by simulation of global changes with soil transplant and

691 cropping, ISME. J., 8(10), 2045-2055, 2014.

692

693 Zhou, J., He, Z., Yang, Y., Deng, Y., Tringe, S.G., Alvarez-Cohen, L.: High-throughput

694 metagenomic technologies for complex microbial community analysis: open and closed formats,

695 MBio., 6(1), e02288, 2015.

696 